\title{
Antimicrobial Activity of Cladosporium oxysporum Endophytic Fungus Extract Isolated From Aglaia odorata Lour
}

\author{
Noor Erma Sugijanto, Bella Lexmita Dorra
}

Faculty of Pharmacy, Airlangga University

\begin{abstract}
Background: Endophytic fungi have economic potential as enzymes, medicines and biological control agents. Cladosporium oxysporum endophytic fungi can be isolated from a plant named Aglaia odorata Lour (Indonesian: Pacar Cina). This plant can be found in Purwodadi Botanical Garden, Pasuruan, East Java. This study aimed to assess the antimicrobial activity from the ethyl acetate extract of the Cladosporium oxysporum endophytic fungi against Escherichia coli, Staphylococcus aureus, and Candida albicans.

Subjects and Method:This was a descriptive study. C. oxysporum was cultivated, extracted, and fractionated. The fractions then were applied to antimicrobial activity assay. Disc diffusion method was used in this project with $2 \mathrm{mg} /$ disc concentration extracts.

Results: Some fractions of ethyl acetate extracts C.oxysporum showed antimicrobial activity against all microbials tested. 6 of 13 fractions exhibited inhibition zone against $S$. aureusATCC 6538, E. coli ATCC 8739, and C. albicansATCC 10231. The seventh fraction exhibited the highest inhibition zone against $S$. aureus ATCC 6538, and C.albicans ATCC 10231.The tenth fraction exhibit edthe highest zone against $E$. coli ATCC 8739.

Conclusion: Cladosporium oxysporum from Aglaia odorata could be a good source of antimicrobial substance. It produces bioactiveagent that can be developed into a new drug at a larger commercial scale.
\end{abstract}

Keywords: endophytic fungi, cladosporium oxysporum, aglaia odorata lour, antimicrobial activity

\section{Correspondence:}

Noor Erma Sugijanto, Bella Lexmita Dorra. Faculty of Pharmacy, Airlangga University.

\section{BACKGROUND}

Endophytic fungi potentially important in the future as source of raw materials for drugs, antibiotics, enzymes, insectides and plan growth hormones (Pimentel et al., 2010; Stribel and Daisy 2003). Endophytic fungi potentially economically important in the future as a source of raw materials for drugs, antibiotics, enzyme, insecticides and plant growth hormones (Pimentel et al., 2010; Strobel and Daisy, 2003). Endophytes produce secondary metabolites to protect itself and its host of pest nematodes, mammals, insects, bacteria and fungi pathogens (Tan and Zou, 2001).
Nowadays the need to obtain new antimicrobial compounds to overcome the resistance of pathogenic microbes cause various infectious diseases in particular developing tropical region, e.g. tuberculosis and malaria is urgent. On the otherhand, endophytic fungi are known to produce bioactive metabolites among others efficacious antimicrobial, it is necessary to do research to determine new antimicrobial compounds from endophytic fungi in Indonesia's rich of biodiversity.

Endophytic microbes may include bacteria, actinomycetes and fungi that live inter and intra-cellular in healthy plant tissue. Endophytic fungi store unlimited potential as a source of valuable natural ma- 
terials for medicine raw materials (Nalini et al., 2005). Strobel (2002) said most endophytic been investigated, mostly a source of antibiotics.

Redell and Gordon (2000) as quoted by Strobel and Daisy, 2003 declared endophyte in tropical rain forest environment is superior and is a source of metabolites of novel and biologically active. Reported by Bills et al., 2002 endophyte tropical provide a more active metabolite and vary very significantly from the endophyte from subtropical climates (Strobel and Daisy, 2003). Indonesia biological resources, particularly endophytic microbes have not been studied and utilized, whereas its potential as a source of valuable active ingredients and compounds (novel substances) is very large. Nine kinds of compounds that have been isolated from Lecythophora sp. endophytic fungus derived from Alyxia reinwardtii BL (pulasari) shown to have antimicrobial activity and a variety of other activities (Sugijanto et al., 2009; 2011).

Aglaia odorata Lour (Indonesian: Pacar Cina) is an Indonesian medicinal plants usedfor abdominal bloating, difficulty swallowing, cough, dizziness, bruises, sores, body odor and diarrhea (Hariana, 2005). Various endophytic fungi have been isolated from Aglaia odorata one Cladosporium oxysporum that the initial testing of ethyl acetate extracts showed antimicrobial activity (Sugijanto et al., 2005). There may be a variety of bioactive compounds in the extract, it is necessary to do the separation (fractionation and isolation) the active compound is more effective when it is guided by the activity test (isolation guidance by activity).

The study aimed to determine the antimicrobial activity of the extract fractions endophytic fungus Cladosporium oxysporumaga-inst microbes Escherichia coli, Staphylococcus aureus and Candida albicans.
Long-term goal acquired potent new antimicrobial finding efficacious and safe so that it can be used as raw material for medicine.

\section{SUBJECTS AND METHOD \\ Materials}

Host plants obtained from Purwodadi, East Java and have been identified as Aglaiaodorata by LIPI- Purwodadi. The endophytic fungus Cladosporium oxysporum isolated from Aglaia odorata according to the procedure Sugijanto et al., (2009) and identified by Pharmazeutische Institutefür Biologie, Universität Düsseldorf with mushrooms code AGO by Dr. Arnulf Diesel (Düsseldorf University).

Microbial testing: Staphylococcus aureus ATCC 6538 (gram-positive), Escherichia coli ATCC 8739 (Gram negative) and the fungus Candida albicans ATCC 10231 was obtained from P.T. Otsuka, Indonesia. Test bacteria were identified by Gram staining and Lactofenol Cotton Blue for Candida albicans before use.

Materials used media agar (food grade), malt extract (E. Merck), Saboroud 2\% dextrose broth (Oxoid, CMI), potatoes dextrose agar (Difco), and nutrient broth (Oxoid, CMI). Chemicals, used $\mathrm{NaCl}$ (P.A., E. Merck), ethyl acetate, methanol, n-hexane and dichloromethane P.A. (Mallinckrodt Baker Inc., Philipsburg, NJ), chloroform (P.A., E. Merck), TLC plates Silicagel 6o F254, and silicagel $60 \mathrm{G}$ for column (E.Merck). Streptomycin sulfate (PT. Meiji Indonesia) as a positive control for antibacterial and ketoconazole (pharmaceutical grade, P.T. Bernofarm, Surabaya) as the benchmark for anti-fungal.

Tools used autoclave (Huxley HL-340 Speedy), laminair air flow cabinet (Dalton), an analytical balance (Mettler Toledo $\mathrm{AB}$ 204-s), pH-meter (Fischer Accumet-230A), chamber chromatography (Camag),UV light, 
spectrophotometer UV-Vis (Lambda EZ 201 Perkin Elmer) and Hitachi F-40oo.

\section{Cultivation of endophytic fungi}

Cladosporium oxysporum isolated preserved in malt extract agar, rejuvenated every six months, stored at a temperature of $5^{-}$ $10^{\circ} \mathrm{C}$. Preparation of inoculum for cultivation in liquid media, do rejuvenation in advance by way of one loop of endophytic fungi from parent cultures were grown in malt extract agar medium and incubated 7 days. One OSE inoculum was 7 days, grown in $40 \mathrm{ml}$ of liquid malt extract medium with a pH of 5.6 in a $300 \mathrm{ml}$ Erlenmeyer flask. Cultures were incubated stationary (static culture) at room temperature and harvested at 28 days (Sugijanto et al, 2009). Mass cultivation is done within $\pm 13.2 \mathrm{~L}$ liquid medium (431 bottle culture).

\section{Extract Preparation}

Cladosporium oxysporum metabolite extraction is done by homogenous biomass and liquid in the blender. Subsequently extracted with ethyl acetate half its volume, was ultrasonic for fifteen minutes and shaken with rotary-shaker for 1 hour and separated by a separating funnel. Extraction is repeated three times and the ethyl acetate extract was concentrated by vacuum rotary evaporator at a temperature of $35^{\circ} \mathrm{C}$.

\section{Fractionation of secondary metabo- lites}

The ethyl acetate extract $( \pm 2.8 \mathrm{~g}$ ) was fractionated by column chromatography (CC) (Cannell, 1998). The stationary phase Silica gel 60 for column chromatography ( \pm 200 $\mathrm{g}$, size 70-230 mesh), eluted beginning with $\mathrm{n}$-hexane. Elution continued with n-hexane: ethyl acetate (1:1) (v/v); n-hexane: ethyl acetate (1:9) (v/v) to ethyl acetate 100\%, then ethyl acetate: methanol (9: 1) (v $/ v)$ with a gradient of $10 \%$ to $100 \%$ methanol. Results separation accommodated in the vial. Every 5 vials and analyzed multiples thin layer chromatography (TLC) us- ing Silica gel 60 F254 plates with stains UV at $\lambda 254$ and anisaldehyde sulphuric acid. TLC results were the same color stain and $\mathrm{Rf}$ combined in one faction, and the fractions of the tested antimicrobial activity.

\section{Test of antimicrobial activity}

Test of antimicrobial activity performed diffusion disc (disc diffusion method) (Doughari, 2006). Medium test used Saboroud $2 \%$ dextrose agar for fungi and nutrient agar for bacteria. Microbial inoculum preparation of test done by a loop of the culture was taken inventory of each colony, surface streaking agar slant and incubated 24 hours at a temperature of $37-38^{\circ} \mathrm{C}$ for bacteria and $32-33^{\circ} \mathrm{C}$ for mushrooms. Microbial cultures age test 24 hours added $10 \mathrm{~mL}$ of sterile $0.9 \%$ sodium chloride, and transmittance measured with a spectrophotometer at a wave length of $580 \mathrm{~nm}$ to achieve 25\% transmittance (Ministry of Health, 1995). Mushrooms test prepared by a fungus use inserted a tube containing 10 $\mathrm{mL}$ of sterile distilled water diluted to obtain a suspen-sion with $90 \%$ transmittance at a wave length of $540 \mathrm{~nm}$.

Created test solutions of each fraction were already known weight, was dissolved to obtain a level of $100,000 \mathrm{ppm}$. $20 \mathrm{~mL}$ of test solution in drops to a paper disk (disc), which is equivalent to $2 \mathrm{mg} /$ disc. As a positive control in drops $20 \mathrm{~mL}$ streptomycin sulfate $100 \mathrm{ppm}, 20 \mathrm{~mL}$ solution of 2000 ppm for antifungal ketoconazole and $20 \mathrm{~mL}$ ethyl acetate as a negative control.

Suspension microbes (each $10 \mathrm{~mL}$ for C. albicans, S. aureus and E. coli) was added to $15.0 \mathrm{ml}$ of sterile media that melted (temperature $\pm 45^{\circ} \mathrm{C}$ ), homogenized, immediately poured into a petri dish and left to solidify. Petri dishes containing media and microbes are added the paper disk that already contains the test solution and the positive and negative controls. The bacteria were incubated at $37^{\circ} \mathrm{C}, 32^{\circ} \mathrm{C}$ for the fungi 
for 24-48 hours. After 24-48 hours, a clear zone (diameter of inhibition) was measured with calipers. Replication is done three times for each of the fractions and microbes.
The results obtained ethyl acetate extract $5.52 \mathrm{~g}$, yellowish brown. Furthermore, $2.8 \mathrm{~g}$ fractionated by column chromatography, TLC analyzed the results obtained after 13 fractions. The test results antimicrobial extract fractions C.oxysporum presented in Table 1 to 3 .

\section{RESULTS} Table 1.Results of Antimicrobial Test fraction extracts against microbes C.
oxysporum E. coli ATCC 8739 oxysporum E. coli ATCC 8739

\begin{tabular}{|c|c|c|c|c|c|c|}
\hline \multirow{2}{*}{$\begin{array}{l}\text { Fraction } \\
\text { Number }\end{array}$} & \multicolumn{2}{|c|}{$\begin{array}{l}\text { Positive Control Inhibition Zone } \\
\text { (Streptomisin) }\end{array}$} & \multicolumn{2}{|c|}{ Inhibition Zone Test Fraction } & \multirow{2}{*}{$\begin{array}{c}48 \\
\text { hours }\end{array}$} & \multirow{2}{*}{$\begin{array}{l}120 \\
\text { hours }\end{array}$} \\
\hline & $\begin{array}{l}\text { DiameterAverage } \\
\pm \mathrm{SD}(\mathrm{mm})\end{array}$ & RSD (\%) & $\begin{array}{c}\text { Diameter Average } \\
\pm \mathrm{SD}(\mathrm{mm})\end{array}$ & RSD (\%) & & \\
\hline 1. & $18.20 \pm 1.56$ & 8.58 & - & - & - & - \\
\hline 2. & $18.20 \pm 1.56$ & 8.58 & - & - & - & - \\
\hline 3. & $18.20 \pm 1.56$ & 8.58 & $8.45 \pm 0.53$ & 6.26 & -- & -- \\
\hline 4. & $18.20 \pm 1.56$ & 8.58 & $11.90 \pm 1.46$ & 12.27 & -- & -- \\
\hline 5 . & $18.20 \pm 1.56$ & 8.58 & $12.67 \pm 1.10$ & 8.67 & -- & -- \\
\hline 6. & $19.20 \pm 1.03$ & 5.38 & $13.98 \pm 1.63$ & 11.67 & + & + \\
\hline 7. & $18.20 \pm 1.56$ & 8.58 & $18.41 \pm 1.56$ & 8.46 & + & + \\
\hline 8. & $19.20 \pm 1.03$ & 5.38 & - & - & - & - \\
\hline 9. & $19.20 \pm 1.03$ & 5.38 & - & - & - & - \\
\hline 10. & $19.50 \pm 0.59$ & 3.02 & $19.50 \pm 1.00$ & 5.12 & + & + \\
\hline 11. & $19.50 \pm 0.59$ & 3.02 & - & - & - & - \\
\hline 12. & $19.20 \pm 1.03$ & 5.38 & - & - & - & - \\
\hline 13 . & $19.50 \pm 0.59$ & 3.02 & - & - & - & - \\
\hline
\end{tabular}

Information:

(--) There was growing around the inhibition zone,

(+) Remain clear inhibition zone

Table 2. The antimicrobial activity of the ethyl acetate extracts fraction C. oxysporum against Staphylococcus microbes, aureus ATCC 6538

\begin{tabular}{ccccccc}
\hline \multirow{2}{*}{$\begin{array}{c}\text { Fraction } \\
\text { Number }\end{array}$} & \begin{tabular}{c} 
Positive Control (Streptomycin) \\
\cline { 2 - 5 }
\end{tabular} & $\begin{array}{c}\text { Inhibition zone test fraction } \\
\text { SD (mm) }\end{array}$ & RSD (\%) & $\begin{array}{c}\text { Diameter Average } \\
\text { SD }(\mathrm{mm})\end{array}$ & RSD (\%) & 120 \\
hours & Hours \\
\hline 1. & $14.98 \pm 1.36$ & 9.09 & - & - & - & - \\
2. & $14.98 \pm 1.36$ & 9.09 & - & - & - & - \\
3. & $14.98 \pm 1.36$ & 9.09 & $8.32 \pm 0.14$ & 1.74 & + & + \\
4. & $14.98 \pm 1.36$ & 9.09 & $12.72 \pm 2,12$ & 16.69 & + & + \\
5. & $14.98 \pm 1.36$ & 9.09 & $16.53 \pm 1.13$ & 6.80 & + & + \\
6. & $18.40 \pm 2.48$ & 13.50 & $13.30 \pm 0.85$ & 6.42 & + & + \\
7. & $14.98 \pm 1.36$ & 9.09 & $18.52 \pm 2.27$ & 12.24 & + & + \\
8. & $18.40 \pm 2.48$ & 13.50 & - & - & - & - \\
9. & $14.98 \pm 1.36$ & 9.09 & $7.15 \pm 0,13$ & 1,85 & - & - \\
10. & $18.40 \pm 2.48$ & 13.50 & $13.22 \pm 1.03$ & 7.77 & + & + \\
11. & $18.40 \pm 2.48$ & 13.50 & $7.88 \pm 0.57$ & 7.21 & + & + \\
12. & $18.40 \pm 2.48$ & 13.50 & - & - & - & - \\
13. & $18.40 \pm 2.48$ & 13.50 & - & - & - & - \\
\hline
\end{tabular}


Indonesian Journal of Medicine (2016), 1(2): 108-115

https://doi.org/10.26911/theijmed.2016.01.02.04

Table 3. The antimicrobial activity of the ethyl acetate extract fraction C. oxysporum against microbes C.albicans ATCC 10231

\begin{tabular}{ccccccc}
\hline & \multicolumn{2}{c}{$\begin{array}{c}\text { Positive Control } \\
\text { (Ketokonazol) }\end{array}$} & \multicolumn{2}{c}{$\begin{array}{c}\text { Inhibition Zone Test } \\
\text { Fraction }\end{array}$} & 48 & 120 \\
\cline { 2 - 5 } Number & $\begin{array}{c}\text { Average } \\
\text { Diameter } \pm \text { SD } \\
\text { (mm) }\end{array}$ & $\begin{array}{c}\text { RSD } \\
\text { (\%) }\end{array}$ & $\begin{array}{c}\text { Average } \\
\text { Diameter } \\
\pm \text { SD (mm) }\end{array}$ & $\begin{array}{c}\text { RSD } \\
\text { (\%) }\end{array}$ & Hours & Hours \\
\hline 1. & $11.8 \pm 0.48$ & 4.09 & - & - & - & - \\
2. & $11.8 \pm 0.48$ & 4.09 & - & - & - & - \\
3. & $11.8 \pm 0.48$ & 4.09 & $9.18 \pm 1.16$ & 12.6 & + & + \\
4. & $11.8 \pm 0.48$ & 4.09 & $7.42 \pm 0.64$ & 8.56 & -- & - \\
5. & $11.8 \pm 0.48$ & 4.09 & $15.7 \pm 1.21$ & 7.72 & + & + \\
6. & $11.0 \pm 0.49$ & 4.48 & $14.0 \pm 1.70$ & 12.1 & + & + \\
7. & $11.8 \pm 0.48$ & 4.09 & $26.8 \pm 0.72$ & 2.69 & + & + \\
8. & $11.0 \pm 0.49$ & 4.48 & - & - & - & - \\
9. & $11.8 \pm 0.48$ & 4.09 & $8.23 \pm 0.98$ & 11.9 & -- & - \\
10. & $11.0 \pm 0.49$ & 4.48 & $19.9 \pm 0.63$ & 3.18 & + & + \\
11. & $11.0 \pm 0.49$ & 4.48 & $8.87 \pm 0.71$ & 7.98 & + & + \\
12. & $11.0 \pm 0.49$ & 4.48 & $9.55 \pm 1.56$ & 16.3 & + & + \\
13. & $11.0 \pm 0.49$ & 4.48 & - & - & - & - \\
\hline
\end{tabular}

Fraction 3, 4, 5, 6, 7, and provide inhibitory zone 8.05 to $20.15 \mathrm{~mm}$ on Eschrichia coli ATCC 8739, and a fraction to-10 provides the greatest inhibition zone diameter. Fraction to 6,7 and 10 provide power resistor which last up to 120 hours.Fraction 3 , 4, 5, 6, 7, 9, 10 and 11 showed the inhibition zone diameter from 7.00 to20.40 $\mathrm{mm}$ on $\mathrm{S}$. aureus ATCC 6538 last up to 120 hours. Fraction to -7 provides the greatest inhibition zone diameter on S. aureus ATCC 65 38. Fraction to 3, 4, 5, 6, 7, 9, 10, 11 and 12 provide inhibition zone on C. albicans ATCC 10231 between 7.05 to $27.40 \mathrm{~mm}$. the inhibitory effects last up to 120 hours except the fraction of the $4^{\text {th }}$. Fraction $7^{\text {th }}$ provides the greatest diameter of inhibition zone on C. albicans ATCC 10231.

\section{DISCUSSION}

Metabolic extraction with semi-polar solvent is ethyl acetate with consideration of a variety of bioactive metabolites produced endophytic fungi is generally semi-polar and extracted well by ethyl acetate. The solvent is ethyl acetate that is semipolar has a large solubility for phytochemical compounds (phytoconstituents) effacious antimicrobial (Doughari, 2006).

Fractionation and antimicrobial test results showed 6 to 13 fractions giving inhibition zone on Gram positive, negative and fungi that S. aureus ATCC 6538, ATCC 87 39 E. coli and C. albicans ATCC 10231 at 24 hours incubation (Table 1-3). Fraction $3^{\text {rd }}$ to $7^{\text {thand }} 10^{\text {th }}$ fractions showed activity with a broad spectrum in three microbes were fractions 9 and 11 seem to be more sensitive to Gram positive bacteria (S. aureus ATCC 6538) and fungi (C. albicans ATCC 10231). Fraction $7^{\text {th }}$ provides the greatest diameter of inhibition zone on S. aureus ATCC 6538 and C. albicans ATCC 10231. E. coli ATCC 8739 fraction $10^{\text {th }}$ provides the greatest inhibition zone diameter. A test extract more active on Gram negative or Gram positive bacteria and fungi need for caution in terms of the difference in the diameter of inhibition zone formed. This is due to other 
factors that influence such as the amount of inoculum and homogeneous or whether the extract solution (Raviraja et al, 2005).

The observation after 48 and 120 hours incubation showed changes to the inhibition zone on a few fractions. The presence of growth inhibitory zone around the fraction shown by 3, 4, 5 in E. coli, fraction $9^{\text {th }}$ in S. aureus; as well as fraction of the $4^{\text {th }}$ and $9^{\text {th }}$ in C. albicans, significant fractions. In contrast to the fraction of the 6th, 7 th and 1oth in E. coli; fraction of the 3rd, 4, 5, $6,7,10$ and 11 in S. aureus; as well as the fraction of the 3rd, 5, 6, 7, 10, 11 and 12 in C. albicans showed inhibition zone which remains clear for 48 and 120 hours. The absence of microbial growth inhibition zone in the area for more than 24 hours is assumed that the test materials are bactericide and fungicide (Doughari, 2006), although it needs further study.

The existence of some fraction of the extract of C. oxysporum cannot inhibit the growth of microbes, may be due to the test material with a level of $2 \mathrm{mg} /$ disk phytochemical compounds (phytoconstituents) are efficacious antimicrobial present in relatively small concentrations that are not able to fight microbes. Factors that influence and should be considered in testing the antimicrobial activity with this method include the concentration of the bacteria were added to the media (the amount of inoculum), contamination of pathogens, the diffusion effect of antibiotics used, the thickness of media, incubation temperature, incubation time and the nutrients media, Strains of microorganisms used test should also be considered because the strains are different, there are different levels of sensitivity to the test compounds (Hostettmann, 1991). ,

Microbial samples used in this study represent bacteria and fungi that cause diseases such as skin infections, acne, boils, cystitis, pyelitis (Staphylococcus aureus), diarrhea and indigestion (Escherichia coli) and vaginal discharge in women or candidiasis (Candida albicans) (Hostettmann, 1991).

Differences genus and endophytic fungal strains will produce different antimicrobial activity (Wang et al., 2007). Fractions and isolates brefeldina compound of Clado sp. in plants Quercusvariabilis has antimicrobial activity against Trichophytonrubrum, Candida albicans, Aspergillusniger, Esche coli, Bacillus subtilis and Pseudomonas aeruginosaWang (2007). Phenolic comp and polyphenols include flavonoids and alkaloids generally have pharmacological properties as an antimicrobial (Pena et al., 2011) are also groups of terpenoids, seskuiterpen, steroids, essential oils, lectin and a polypeptide known to play a role in the antimicrobial activity (Cowan, 1992).

In a study of metabolite profile in the TLC-densitometry C. oxysporum fungus isolated from Aglaiaodorata compound obtained steroids, terpenoids, seskuiterpen and the ethyl acetate extract (Winarti, 2005). Such compounds are thought to play a role in the antimicrobial activity of the existing fractions. This indicates secondary metabolites have antimicrobial activity, are produced as a defense mechanism against bacterial and fungal pathogens to its host. Production of bioactive compounds is efficacious antimicrobial by endophyte, as was already known due to the specificity of the biological condition of host plants and endophyte to protect from pathogens (Strobel and Daisy, 2003).

Conclusion: The results of the fractionation Cladosporiumoxysporum ethyl acetate extract obtained 13 fractions, 6 fractions including providing test microbial inhibition zone against Staphylococcus aureus ATCC 6538, Escherichia coli ATCC 8739 and Candida albicans ATCC 10231 at $24 \mathrm{~h}$ 
incubation. 8 fractions of 13 fractions giving inhibition against Staphylococcus aureus ATCC 6538; 6 fraction inhibits Escherichia coli ATCC 8739 and 9 fractions provide barriers against Candida albicans ATCC 10231. Fraction 3rd to 7 th and 10th fractions showed activity with a broad spectrum against all three microbes.

The next steps necessary purification and isolation of the metabolites of fractions as antimicrobial active extract of Cladosporiumoxysporum and characterization and structure elucidation and the testing of pure isolates with microbes that are resistant to existing antimicrobial. C.oxysporuminventtionendophytic fungi that can produce a variety of bioactive metabolites open new opportunities to perform drug production on a commercial scale from microbes hidden inside the host plants.

\section{REFERENCE}

Bills G, Dombrowski A, Pelaez F, J and AnPolishook Z (2002). Recent and futurediscoveries of pharmacologically active metabolites from tropical fungi, In Watling $\mathrm{R}$, Frankland JC, Ainsworth $\mathrm{AM}$, Issac $\mathrm{S}$, and $\mathrm{CH}$ Robinson (ed). Tropical Mycology: Micromycetes. New York, CABI Publishing 2: 165-194.

Cannell RJP (1998). Natural products isolation. Totowa, New Jersey Humana Press: 45 -52.

Cowan MM (1999). Plant products as an antimicrobial agent. Clinical Microbiology Review 12 (4): 564-582

Doughari JH (2006). Antimicrobial Activity of Tamarandus indica Linn. Tropical Journal of Pharmaceutical Research, (5): 597-603.

Hariana A (2005) Plant Medicine and Usefulness, Depok, Penebar Governmental, 2:154.
Hostettmann K(1991) Methods in plant biochemistry. Institute of Pharmacognosy and Phytochemistry, Switzerland: 47-69.

Ministry of Health (1995). Indonesian Pharmacopoeia Fourth Edition. Ministry of Health of the Republic of Indonesia, Jakarta: 855, 896-897.

MR Pimentel, Molina G, Dionisio AP, Junior MRM, Pastore GM (2010). The used of endophytes to Obtain bioactive compounds and their application in biotransformation process. Biotechnology Research International 2011.

Nalini MS, Mahesh B, Tejesvi MV, HS Prakash, Subbaiah V, KR Now, Shetty HS (2005). Fungal endophytes from the three-leaved caper Crataeva magna (Lour.) DC (Capparidaceae). Mycopathologia 159: 245-249.

Pena CJ, Reverte A, LB Hernandes, Meraz S, Jimenez M, Garcia AM, Avilla G, Hernandes $\mathrm{T}$ (2011). Antimicrobial, antioxidant and toxic effects of Sennaskinneri Bentham, Irwin and Barneby (Leguminoseae), Journal of medicinal plants research 5 (14): 32243228.

Sugijanto NE, Indrayanto G, Zaini NC (2005). The new paradigm of production of cytotoxic medicinal use of the plant endophytic fungi Alyxiareindwarti.

(2009). Chemical constituents of the Endophytic fungus Lecythophora sp. isolated from Alyxiareinwardtii, Natural Product Communications 4 (11): 1485-1488.

- (2011). Lecythomycin, a new macrolactone Lecythophora glycolside from Endophytic fungus sp. Natural Product Communications 6 (5): 677678. 
Raviraja NS (2005). Fungal endophytes in five medicinal plant species from Kudremukh Range, Western Ghats of India. J. Basic Microbiol 45 (3): 230235 .

Redell P, Gordon V (2000). Lesson from nature: ecology can provide new leads in the search for novel bioactive chemicals from rainforest? In Wrigley SK, Hayes MA, Thomas EJ, Chrystal $\mathrm{T}$, and Nicholson N, (ed). Biodiversity: new leads for the pharmaceutical and agrochemical industries. Cambridge, UK, The Royal Society of Chemistry: 205-212.

Strobel GA (2002). Microbial gifts from rain forests. Can J. Plant Pathol 24: 1420.
Strobel G, Daisy B (2003). Bioprospecting for microbial endophytes and their natural products.Microbiol. Mol. Biol. Rev.67 (4): 491-502.

Tan RX, Zou WX (2001). Endophytes a rich source of functional metabolites. Nat. Prod. Rep 18: 448-459.

Wang FW, RH Jiao, Cheng AB (2007). Antimicrobial potentials of Endophytic fungi residing in Quercusvariabilis and brefeldin A Obtained from Cladosporium sp. World J. MicrobiolBiotechnol 23: 79-83.

Winarni CDB (2005). Studies metabolite profiles endophytic fungus Cladosporiumoxysporum of Aglaiaoorata Lour by TLC-densitometry, Thesis, Pharmacy Faculty of Airlangga University. 